\title{
INTERPRETASI CITRA DIGITAL PENGINDERAAN JAUH UNTUK PEMBUATAN PETA LAHAN SAWAH DAN ESTIMASI HASIL PANEN PADI
}

\author{
Herliyani Farial Agoes ${ }^{(1)}$, Faris Ade Irawan ${ }^{(1)}$, Rhima Marlianisya ${ }^{(2)}$, \\ hfagoes@poliban.ac.id, faris.irawan@poliban.ac.id \\ (1) Staf Pengajar Jurusan Teknik Sipil, Politeknik Negeri Banjarmasin, (2) Praktisi \\ Teknik Sipil
}

\begin{abstract}
Ringkasan
Indonesia merupakan Negara agraris yang sebagian wilayahnya adalah pertanian dan perkebunan, dan diharapkan dapat lebih meningkatkan produksi agraris tersebut lewat lahan-lahan sawah dan pertanian yang lebih luas lagi. Sawah merupakan media atau sarana untuk memproduksi padi. Sawah yang subur akan menghasilkan padi yang baik. Lokasi penelitian ini merupakan slah satu kecamatan di Provinsi Kalimantan Selatan yang memiliki lahan sawah yang cukup luas. Lokasi penelitian ini adalah Kecamatan Sungai Raya yang berada di Kabuaten Hulu Sungai Selatan. Kecamatan Sungai Raya memiliki luas wilayah 80,96 km2 dan memiliki lahan sawah menjadi sektor pertanian yang memiliki nilai panen tinggi pada daerah tersebut. Penelitian ini bertujuan untuk mengetahui luasan dan estimasi panen padi, serta pembuatan peta lahan sawah hasil interpretasi citra satelit Worldview2 perekaman tahun 2015. Perhitungan luas area lahan sawah hasil interpretasi citra dihitung dengan menggunakan calculate geometry. Perhitungan luas estimasi panen padi dilakukan dengan acuan dari luas lahan hasil interpretasi dan produktivitas perhektar yang didapat dari Dinas Pertanian. Uji ketelitian interpretasi dilakukan dengan cek lapangan untuk pengambilan data secara sampling (Ground Truth). Hasil dari uji ketelitiandari hasil interpretasi ini adalah 90\%, Dari hasil interpretasi lahan sawah dibuat menjadi peta lahan sawah dengan skala $1: 60.000$. Hasil dari perhitungan luas dengan menggunakan calculate geometry, luas lahan sawah di kecamatan Sungai Raya adalah 2474,802 Ha. Dari acuan luas lahan sawah eksisting yang di dapat dari perhitungan calculate geometry dan dari dari data hasil panen perhektar maka diperoleh hasil estimasi panen padi dengan metode ubinan adalah 17.1969 Ton.
\end{abstract}

Kata kunci: Estimasi panen padi, Citra Worldview2, Interpretasi Citra.

\section{A. PENDAHULUAN}

Sawah merupakan media atau sarana untuk memproduksi padi. Sawah yang subur akan menghasilkan padi yang baik. Indonesia termasuk Negara agraris yang sebagian wilayahnya adalah pertanian, yang dapat memproduksi padi lebih banyak. Namun, karena adanya pembangunan pabrik atau bangunan lainnya di lahan pertanian, menyebabkan produksi pertanian kian berkurang. Tanaman padi (Atom, Siana.2014) termasuk kelompok tanaman pangan yang sangat penting dan bermanfaat bagi kehidupan masyarakat Indonesia. Sehingga apabila terjadi penurunan tingkat produksi dan produktivitas padi secara drastis, maka dapat mempengaruhi ketersediaan beras nasional dan akan berdampak negatif terhadap sektor-sektor lainnya.

Daerah yang dikaji dalam penelitian ini adalah Kecamatan Sungai Raya yang berada di Kabuaten Hulu Sungai Selatan. Kecamatan sungai raya memiliki luas wilayah 80,96 km2. Dan menurut data Badan Pusat Statistik, Luas lahan sawah sebesar 3,171 $\mathrm{Ha}$, maka daerah lahan sawah menjadi sektor pertanian yang memiliki nilai panen tinggi pada daerah tersebut. Oleh karena itu, Kecamatan Sungai Raya mempunyai potensi dalam pertanian. Peta merupakan gambaran permukaan bumi yang dituangkan dalam bidang datar. Peta menunjukkan informasi sesuai tema yang diambil. Peta yang akan dihasilkan pada penelitian ini adalah peta tematik lahan sawah yang dihasilkan melalui digitasi hasil interpretasi citra satelit. Peta terebut dalam bentuk digital sehingga memungkinkan untuk menghitung estimasi produksi panen padi, melalui pendekatan dan perhitungan tertentu. Dalam penelitian ini, pembuatan peta lahan sawah dilakukan karena pihak instansi terkait daerah penelitian belum memiliki peta lahan sawah. Perhitungan estimasi lahan sawah untuk mengetahui berapakah estimasi produksi padi di daerah penelitian, beracukan pada luas tanam sawah yang di dapatkan dari penginderaan jauh, dengan produktivitas per- 
hektar dari instansi terkait. Berdasarkan latar belakang tersebut di atas, perlu dilakukan pembuatan peta lahan sawah dan estimasi hasil panen padi menggunakan penginderaan jauh dan sistem informasi geografis.

\section{B. LANDASAN TEORI}

\section{Pengertian Lahan Sawah}

Sawah adalah tanah berlumpur di lahan datar dengan tekstur tanah berlempung yang keras di bagian dalam sehingga dapat menampung genangan air. Sawah biasanya di buat berpetak-petak yang antara petak yang satu dengan yang lain di batasi oleh pematang. Sawah biasanya di gunakan sebagai lahan untuk menanam padi dan palawija. Pengolahan tanah sawah tergantung dari jenis tanaman yang akan di tanam. Jika yang di tanam adalah padi sawah, maka sawah perlu di genangi air. Tetapi jika yang di tanam adalah sayur-mayur dan palawija, maka sawah akan di keringkan untuk mengurangi kadar airnya.

Sawah dapat di buat di berbagai posisi tanah. Baik yang di pingir pantai ataupun diatas daerah perbukitan dengan tingkat kemiringan yang tinggi. Lahan yang berkemiringan tinggi, sawah dicetak berteras atau berundak-undak untuk menahan air dan menghindari erosi. Sawah yang berundak-undak atau berterasteras di sebut dengan istilah sawah terasering. Sawah berteras banyak terdapat di lerenglereng bukit atau gunung di Jawa, Sumatera dan Bali. (Atom, Siana.2014).

\section{Produktivitas Pertanian}

Seiring dengan berjalannya transformasi struktural di Indonesia, peranan sektor pertanian sebagai komponen pembentuk produk domestik bruto (PDB) akan berkurang. Menurut data Badan Pusat Statistik (BPS), pada 2012 sektor pertanian berkontribusi sekitar $12,51 \%$ terhadap total PDB Indonesia. Nilai ini berada di bawah sektor industri pengolahan yang mencapai $25,6 \%$. Akan tetapi, jika dilihat peranan sektor pertanian dalam penyerapan tenaga kerja nasional yang mencapai $35 \%$, itu jauh lebih tinggi jika dibandingkan dengan sektor industri pengolahan yang hanya menyerap $13,9 \%$ total tenaga kerja nasional.

$\mathrm{Hal}$ tersebut mengindikasikan bahwa produktivitas sektor pertanian Indonesia masih rendah. Secara teoretis, fenomena ini dapat dijelaskan melalui hukum diminishing return. Maksudnya adalah semakin banyak orang yang bekerja di lahan pertanian yang terbatas, nilai tambahan produktivitas mereka akan turun. Ini berimplikasi terhadap memburuknya kualitas kehidupan mereka yang bergerak di sektor pertanian. Kunci untuk memajukan sektor pertanian adalah peningkatan produktivitas. Namun, peningkatan produktivitas ini tidak semudah dengan melakukan modernisasi peralatan pertanian saja. Salah satu solusi untuk memajukan sektor pertanian adalah membantu para petani dalam penyediaan faktor input sektor pertanian, misalnya penyediaan bibit unggul dan pupuk. Sayang Pemerintah Indonesia belum berkomitmen dalam hal ini (Husen Ibnu, 2015).

Dalam APBN 2013 terlihat subsidi untuk pupuk dan benih masing-masing hanya mencapai $5,7 \%$ dan $0,052 \%$ dari total subsidi pemerintah. Nilai ini jauh sangat kecil jika dibandingkan dengan nilai subsidi BBM yang mencapai $56 \%$ total subsidi pemerintah. Solusi untuk memajukan sektor pertanian di Indonesia tidaklah berhenti sampai di sini saja.

Masih banyak kebijakan lain yang harus dilaksanakan untuk membentuk solusi yang komprehensif. Pertama, pembangunan dan pengembangan jaringan irigasi pertanian.Kedua, peningkatan peranan sektor perbankan.Ketiga, perbaikan tata niaga. Terakhir, reformasi agraria agar bukan para pemilik lahan saja yang akan menikmati buah dari sektor pertanian.

Dengan adanya peta sawah yang dihasilkan dari interpretasi citra satelit dengan resolusi spasial dan resolusi temporal yang cukup baik, dapat memberikan informasi dan pendekatan dan estimasi terhadap produktifitaspada saat panen padi nantinya. Sehingga dapat mengukur tingkat keberhasilan program-program yang telah diterapkan Dinas/Instansi terkait.

\section{Metode Ubinan}

Ubinan merupakan survei yang bertujuan untuk mengetahui produktvitas (hasil per hektar) tanaman. Saat ini, tanaman yang bisa diukur produktivitasnya melalui ubinan baru terbatas pada komoditas padi, jagung, kedelai, ubi kayu, dan ubi jalar. Selain angka produktivitas, ubinan juga mencakup data pendukung lainya seperti jenis lahan, cara penanaman, jenis intensifikasi, jenis variates benih, banyaknya benih, pupuk dan pestisida yang digunakan, dan informasi kualitatif terkait produktivitas. Di Indonesia, penghitungan angka produksi padi didapatkan dari angka luas panen yang dikumpulkan oleh mantri tani di tiap kecamatan di Republik Indonesia yang dikalikan dengan angka produktivitas hasil survei ubinan yang dilakukan oleh BPS dan Dinas Pertanian Kabupaten.

Sebagai salah satu survei, ubinan harus mengikuti kaidah-kaidah statistik yang benar dan dapat dipertanggung jawabkan. Metodologi 
yang digunakan yaitu: Ruang lingkup. Ruang lingkup Ubinan mencakup seluruh wilayah Republik Indonesia.Untuk estimasi survei, sampai saat ini telah sampai pada tingkat Kabupaten/Kota sehingga tiap Pemerintah Daerah bisa memiliki angka tersebut dari tingkat Kabupaten/Kota maupun Provinsi. Pengumpulan data ubinan dilakukan sesuai dengan waktu panen yang dilakukan petani. Hasil ubinan tersebut direkap per Sub-Round (empat bulan). (Balitbangtan, 2013 dalam Husen Ibnu, 2015).

\section{Penginderaan Jauh}

Menurut Sutanto (1998) penginderaan jauh adalah ilmu dan seni untuk memperoleh informasi tentang suatu obyek, luasan atau tentang fenomena melalui analisa data yang diperoleh dari sensor dalam hal ini, sensor tidak berhubungan langsung dengan benda yang menjadi target.

Seiring perkembangan zaman banyak bermunculan jenis - jenis citra satelit mulai dari yang memiliki resolusi rendah sampai dengan resolusi tinggi. Citra satelit resolusi tinggi adalah citra - citra satelit yang memiliki resolusi spasial 0,4 - 4 m diantaranya citra dari satelit GeoEye1, WorldView-2, WorldView-1, QuickBird, IKONOS, FORMOSAT-2 dan SPOT-5. Citra satelit resolusi menengah adalah citra - citra satelit yang memiliki resolusi spasial $4-30 \mathrm{~m}$ diantaranya citra dari satelit ASTER, LANDSAT 7 dan CBERS-2.



Gambar 1. Sistem Penginderaan Jauh (Sumber : Eka, 2010)

Sedangkan citra satelit resolusi rendah adalah citra - citra satelit yang memiliki resolusi spasial 30 - $1000 \mathrm{~m}$ diantaranya citra - citra satelit NOAA AVHRR, Terra MODIS dan Aqua MODIS. Semua citra - citra satelit tersebut memiliki fungsi dan keunggulan masing masing.

\section{Pengolahan dan Interpretasi Citra Digital}

Pengolahan citra digital merupakan proses yang bertujuan untuk memanipulasi dan menganalisa citra dengan bantuan komputer.

Pengolahan citra dan pengenalan pola menjadi bagian dari proses pengenalan citra. Kedua aplikasi ini akan saling melengkapi untuk mendapatkan ciri khas dari suatu citra yang akan dikenali. (Sumber : Wells, Risdy. 2010.)

Interpretasi citra adalah tindakan mengkaji foto atau citra dengan maksud untuk mengenali objek dan gejala serta menilai arti pentingnya objek dan gejala tersebut. citra dapat diterjemahkan dan digunakan ke dalam berbagai kepentingan seperti dalam: geografi, komputer, printer dan GPS Hand Held yang digunakan untuk perekaman titik koordinat data di lapangan. geologi, lingkungan hidup dan sebagainya. Pada proses pengolahan data citra pada penelitian ini menggunakan perangkat lunak (Software) ER MAPPER karena mampu melakukan pendekatan yang unik dalam pengolahan data citra yang mengkombinasikan file - based dan band - based.

ArcGIS adalah salah satu software yang dikembangkan oleh ESRI (Environment Science \& Research Institute) yang merupakan kompilasi. fungsi-fungsi dari berbagai macam software GIS yang berbeda seperti GIS desktop, server, dan GIS berbasis web. Software ini mulai dirilis oleh ESRI pada tahun 2000. Produk utama dari ArcGIS adalah ArcGIS desktop, dimana ArcGIS desktop merupakan software GIS professional yang komprehensif dan dikelompokkan atas tiga komponen yaitu : ArcView (komponen yang fokus ke penggunaan data yang komprehensif, pemetaan dan analisis), ArcEditor (lebih fokus ke arah editing data spasial) dan Arclnfo (lebih lengkap dalam menyajikan fungsi-fungsi GIS termasuk untuk keperluan analisis geoprosesing).

\section{METODE PENELITIAN}

Letak Geografis kabupaten Hulu Sungai Selatan terletak antara $2^{\circ} 29^{\prime} 59^{\prime \prime}-2^{\circ} 56^{\prime} 10^{\prime \prime}$ LS dan $114^{\circ} 51^{\prime} 19^{\prime \prime}$ - $115^{\circ} 36^{\prime} 19^{\prime \prime}$ BT. Secara geologis daerah ini terdiri dari pegunungan yang memanjang dari arah timur ke selatan, namun dari arah barat ke utara merupakan dataran rendah alluvial yang kadang-kadang berawa-rawa. Dari arah utara melingkar ke arah barat, Kabupaten Hulu Sungai Selatan di aliri oleh Sungai Amandit bermuara ke Sungai Negara (anak sungai Barito) yang berfungsi sebagai sarana prasarana perhubungan dalam kabupaten dan ke kabupaten lainnya. 


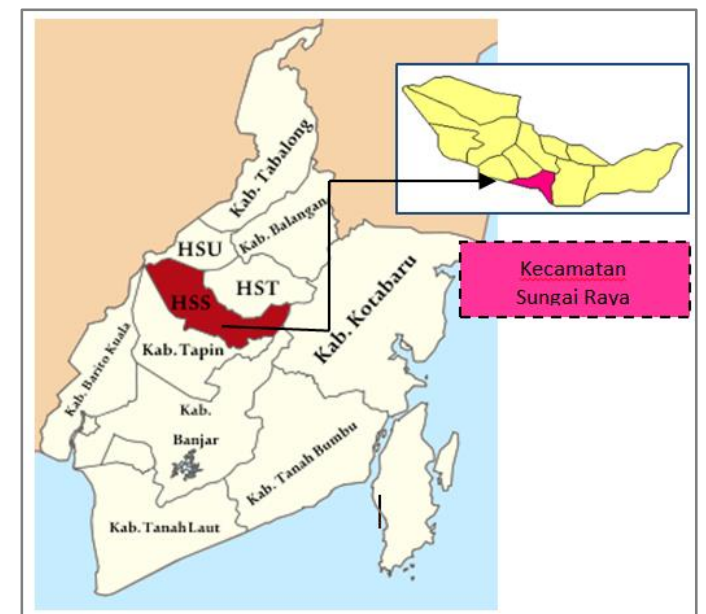

Gambar 2. Lokasi Penelitian, Kabupaten Hulu Sungai Selatan, Kecamatan Sungai Raya

Metode penelitian dari penelitian ini adalah seperti diagram alir di bawah ini :

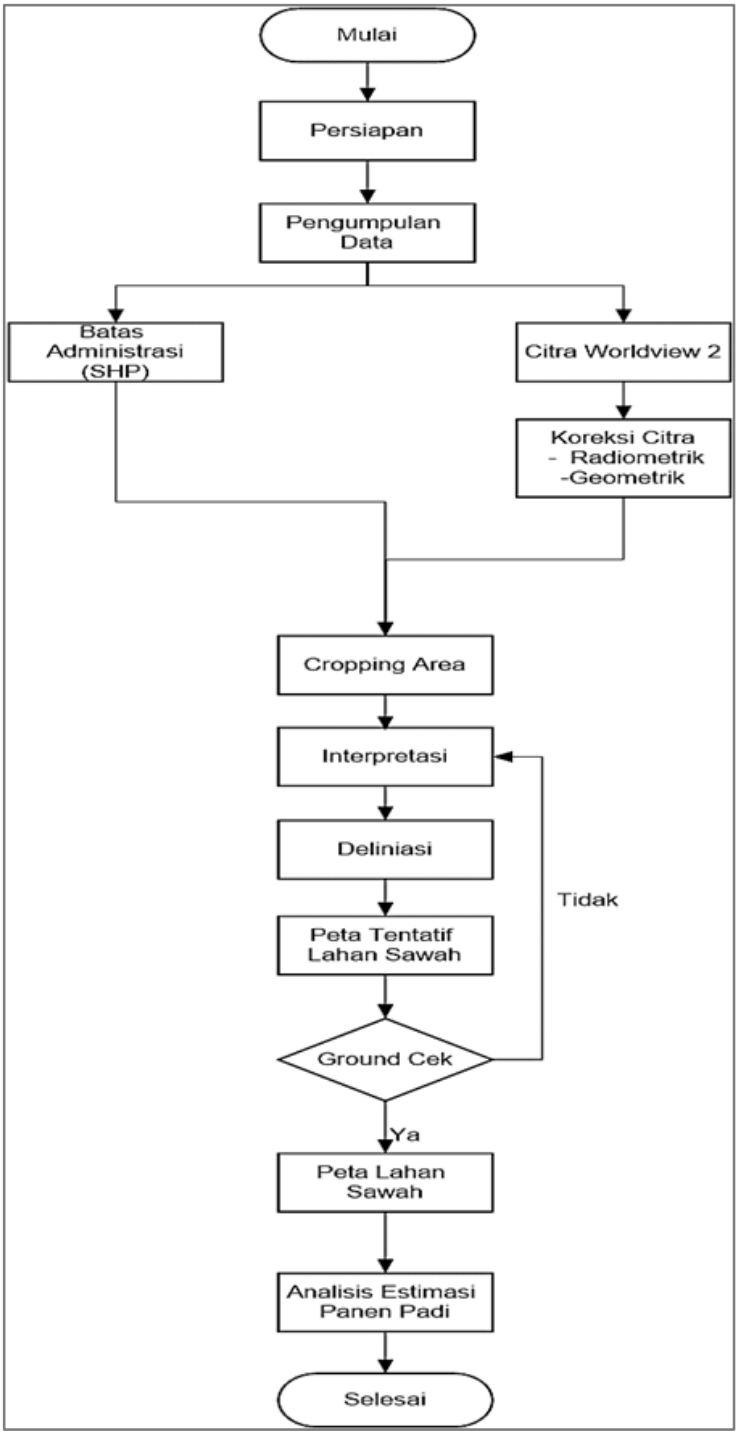

Gambar 3. Diagram Alir Penelitian
Penjelasan Metode Pekerjaan yang tergambar pada diagram alir penelitian di atas adalah sebagai berikut :

1. Interpretasi Citra merupakan proses mengkaji citra dengan maksud untuk mengidentifikasi obyek dan menilai arti pentingnya obyek tersebut. Unsur unsur interpretasi citra adalah :
a. Rona dan warna
b. Bentuk
c. Ukuran
d. Tekstur
e. Pola
f. Bayangan
g. Situs
h. Asosiasi

2. Peta Tentatif merupakan peta hasil interpretasi citra yang masih bersifat sementara dan belum baku.

3. Ground Cek merupakan tahap untuk memeriksa kebenaran dari peta tentative. Toleransi ketelitian interpretasi adalah < $80 \%$. Jika tidak memenuhi syarat, maka tahap interpretasi harus diulang kembali.

4. Peta Lahan Sawah adalah peta yang sudah sesuai atau sudah lolos tahap ground cek lapangan.

5. Analisis Estimasi Panen Padi, merupakan perhitungan estimasi panen dengan parameter berupa luasan lahan tanam dan produktivitas padi perhektar sehingga dapat di hitung estimasi panen padi tersebut.

\section{HASIL DAN PEMBAHASAN}

\section{Koreksi Radiometrik}

Citra sebelum dan sesudah dikoreksi akan memiliki nilai histogram yang berbeda. Adapun dari hasil koreksi radiometrik citra nilai bias 0 dapat diartikan jika citra tersebut sudah terkoreksi terlebih dahulu (Projo Danoedoro, 1996).

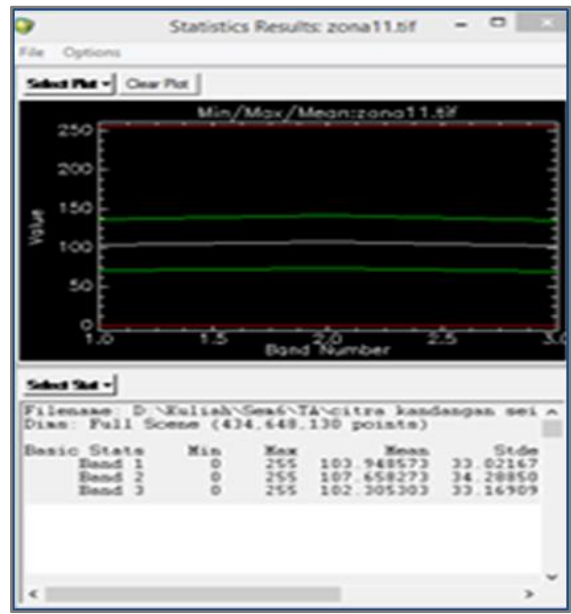

Gambar 4. Koreksi Radiometrik 


\section{Koreksi Geometrik}

Citra yang digunakan untuk penelitian sudah terkoreksi geometrik. Untuk membuktikannya digunakan 1 titik di lapangan pada bundaran ketupat kandangan dengan koordinat $X=306306$ dan $Y=9689064$. Posisi tersebut tepat berada di lokasi dan secara visualisasi mudah dikenali di citra tersebut.

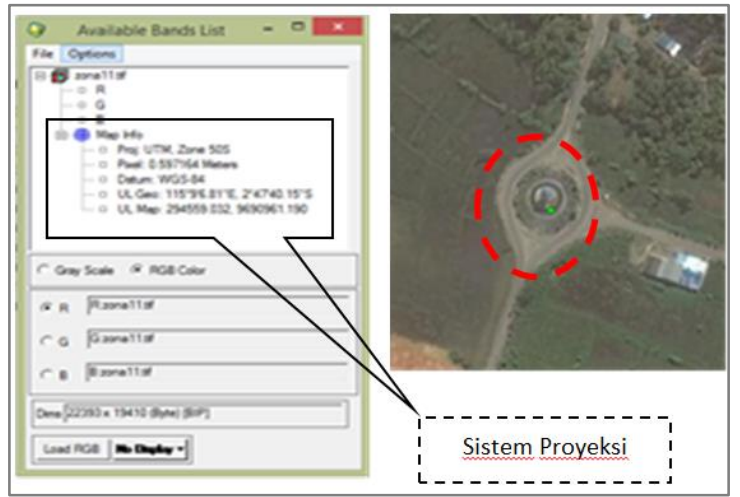

Gambar 5. Koreksi Geometrik

\section{Interpretasi Citra}

Interpretasi citra adalah untuk mengidentifikasi lahan sawah yang ada pada citra Kecamatan Sungai Raya, Hulu Sungai Selatan. Interpretasi lahan sawah dilakukan secara visual dengan acuan pada unsur dan kunci-kunci interpretasi.

Kunci interpretasi yang digunakan seperti warna (padi biasanya terlihat berwarna hijau seperti vegetasi pada umumnya), tekstur (biasanya tanaman padi meiliki tekstur halus, karena daun yang kecil dan merata), bentuk (biasanya persawahan berbentuk persegi), pola (polanya terlihat rapi dan tertata) asosiasi (pada umumnya persawahan memiliki jalur irigasi baik berbentuk permanen maupun alami) dan pendekatan-pendekatan lain yang dapat kita terapkan untuk interpretasi lahan sawah.

Dalam mengenali obyek pada foto udara atau pada citra lainnya, dianjurkan untuk tidak hanya menggunakan satu unsur interpretasi citra. Semakin ditambah jumlah unsur interpretasi citra yang digunakan, maka semakin menciut lingkupnya ke arah titik simpul tertentu. Pengenalan obyek dengan cara ini disebutkonvergensi bukti (cerverging evidence/convergence of evidence).

Tahap selanjutnya kita lakukan analisis dan layout di ArcGis, melalui progam ini, kita dapat menghitung jumlah produktif lahan sawah dan merencanakan titik-titik koordinat untuk dilakukan uji ketelitian interpretasi. Pembuatan peta tentatif Lahan Sawah juga dilakukan pada tahapan ini sebagai tujuan akhir dari proses pengolahan citra digital penginderaan jauh.
Pada gambar 6 di bawah ini menampilkan peta zonasi lahan sawah hasil interpretasi, warna hijau menunjukkan lahan sawah. Dari proses ini dihasilkan kalkulasi luasan lahan sawah di daerah penelitian untuk dilakukan estimasi perhitungan hasil panen padi dilokasi tersebut.

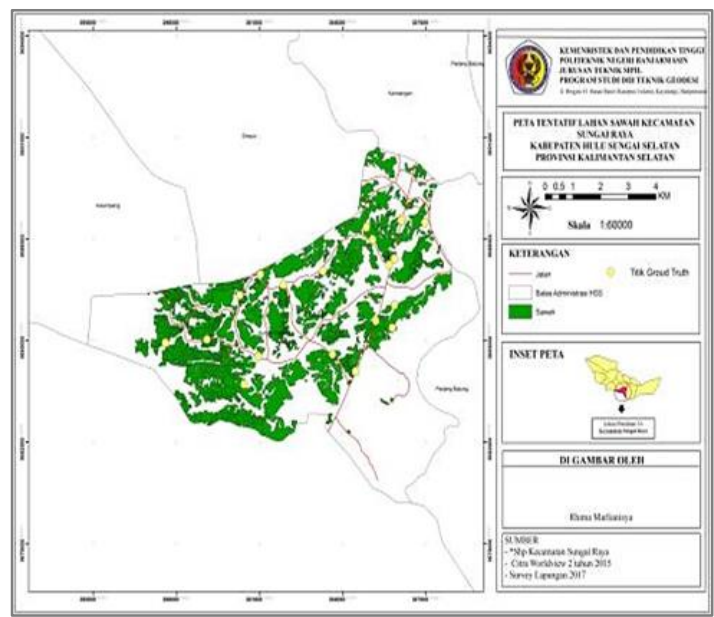

Gambar 6. Hasil Interpretasi Citra

Seperti yang disajikan pada Tabel 7 di Bawah, jumlah titik sampel adalah 50 Titik, dengan metode pengambilan sample adalah Random Sampling.

Ketelitian interpretasi adalah sebagai berikut :

Jumlah Sampel yang Benar : 48

$\begin{aligned} \text { Ketelitian Hasil Interpretasi } & =48 / 50 \times 100 \% \\ & =0.96 \times 100 \% \\ & =96 \%\end{aligned}$

Hasil Groundtruth (validasi lapangan) Hasil interpretasi citra satelit : 


\begin{tabular}{|c|c|c|c|}
\hline Tismor Titik & $x$ & $T$ & Ketenngan \\
\hline PO! & 30004 & ssests! & $5 \mathrm{wA}$ \\
\hline PO: & 303632 & sss:97 & $5 \mathrm{WWH}$ \\
\hline PD) & 1086s: & ssts:y & Srad \\
\hline$P O$ & 10433 & 93388 & Srad \\
\hline POS & $304 ! ! 4$ & ssims & $5 \mathrm{xw2}$ \\
\hline$P O B$ & 304051 & SSLAS4 & $5 \mathrm{sw2}$ \\
\hline का & 105198 & sesssy & Sखले \\
\hline$P B$ & $1058 \%$ & ssssmis & $S_{x \rightarrow 4}$ \\
\hline$\overline{P Q}$ & $1088: 1$ & 953160 & S rod \\
\hline P10 & 30889 & $\operatorname{sis} s$ & $5 \mathrm{xw2}$ \\
\hline PII & 30580 & 9551402 & $5 \mathrm{rrd}$ \\
\hline PII & DSSES & sos?s? & $5 \mathrm{rad}$ \\
\hline$P 13$ & WNY & SOMO15 & $5 \mathrm{sm}$ \\
\hline PIL & $3018 \mathrm{~B}$ & som!3! & Sroz \\
\hline P15 & 306854 & ssst:k & $5 \mathrm{Foz}$ \\
\hline P16 & 1058 & sstisy & $S_{x \times 2}$ \\
\hline pin & 10S63: & sssm & Srod \\
\hline P1S & 30497 & sssisot & $5 x \mathrm{~F}$ \\
\hline P19 & 30478 & SSSS:9 & $5 \mathrm{wat}$ \\
\hline$P D$ & Dowss? & sosuss & 5024 \\
\hline PII & 106675 & gs:413) & $5 \times 2$ \\
\hline P2. & 30409 & sesso: & $5 \mathrm{xrd}$ \\
\hline P23 & 303923 & sssy! & $5 x \mathrm{kz}$ \\
\hline$P M$ & Do138 & 98008 & $S_{\mathrm{rath}}$ \\
\hline PQS & $101 \times 6$ & sosson: & Srat \\
\hline$P X$ & 101864 & $\operatorname{sis} \times 40$ & Srod \\
\hline P27 & $30: 039$ & $\operatorname{sississ}$ & $5 \mathrm{xwz}$ \\
\hline$P 23$ & 300498 & ssajts & $5 \mathrm{rwd}$ \\
\hline PY & 10080 & 48383 & $\$ \mathrm{razh}$ \\
\hline PYO & 10341 & 983445 & Srath \\
\hline P3! & $301: 31$ & ss:sio & Sxod \\
\hline P3: & 301590 & SSSE23 & $5 \times 2$ \\
\hline
\end{tabular}

Gambar 7. Tabel Groundtruth

\section{Perhitungan Luas Lahan Sawah}

Perhitungan hasil luas lahan sawah hasil interpretasi dilakukan pada software ArcGIS dengan option calculate geometry. Yang didapatkan hasil luas sebesar $2474.802 \mathrm{Ha}$.

\section{Estimasi Padi dengan Metode Ubinan}

Pendugaan hasil panen padi hingga saat ini dilakukan dengan menggunakan analisis statistik maupun teknologi citra satelit. Pendugaan hasil panen dengan analisis staistik, membutuhkan banyak data dari pengukuran di lapangan yang kemudian diolah dengan analisis statistik sehingga dapat digunakan untuk menduga hasil panen padi berikutnya (Subrata \& Kusuma, 2003).

Perhitungan produksi padi dengan metode ubinan dilakukan seperti yang dilakukan oleh Badan Pusat Statistik (BPS) dan Dinas Tanaman padi. Ubinan dilakukan dengan mengambil 10 titik sampel dilapangan yang disebar secara acak. Nilai ubinan diperoleh dari hasil survey dilapangan dengan mengambil sampel padi dengan ukuran $2,5 \times 2,5$ meter kemudian dipotong, dirontokkan dan ditimbang. (Said.H.S, Subiyanto.S, Yuwono. B.D., 2015).

Dari beberapa penelitian sebelumnya, nilai ubinan dari titik sampel berkisar 4.7 - 5.6 $\mathrm{Kg}$. Perbedaan ini disebabkan karena tiap daerah memiliki tingkat kesuburan tanah yang berbeda. Untuk penelitian ini, sebagai pendekatan untuk estimasi panen padi dimasukkan nilai ubinan $5,05 \mathrm{Kg}$.

Perhitungan produktivitas dilakukan setelah dihitung nilai ubinan rata-ratanya. Hasil perhitungan produktivitas gabah kering panen (GKP) dihitung dari nilai ubinan rata-rata di kali dengan faktor pengali sebesar 16. Kemudian hasilnya dikalikan dengan konstanta sebesar 0,86 agar menjadi gabah kering giling (GKG).

Dan berikut merupakan rumus perhitungannya:

GKP $=$ Ur $\times 16$

GKG $=\mathbf{G K P} \times 0.86$

Sumber : Dinas Pertanian

Keterangan:

GKP $=$ Gabah Kering Panen (kw/ha)

GKG $=$ Gabah Kering Giling (kw/ha)

Ur $=$ Nilai Ubinan Rata-rata $(\mathrm{kg} / \mathrm{m} 2)$

Dari rumus tersebut maka didapatkanlah hasil sebagaimana di bawah ini :

$$
\begin{aligned}
\text { GKP } & =\mathrm{Ur} \times 16 \\
& =5,05 \times 16 \\
& =80,8 \mathrm{Kw} / \mathrm{Ha} \\
\mathrm{GKG} & =\mathrm{GKP} \times 0,86 \\
& =80,8 \times 0,86 \\
& =69,488 \mathrm{Kw} / \mathrm{Ha}
\end{aligned}
$$

Perhitungan produksi dilakukan setelah nilai gabah kering giling (GKG) dan luasnya diketahui. Nilai produksi diperoleh dari hasil kali antara nilai gabah kering giling (GKG) dengan jumlah luas area tanaman padi di Kecamatan Sungai Raya. Dan berikut merupakan rumus perhitungannya.

\section{Produksi $=$ Produktivitas $\mathrm{GKG} \times$ Luas panen Sumber : Dinas Pertanian}

Dari rumus tersebut maka didapatkanlah hasil sebagaimana di bawah ini :

$$
\begin{aligned}
\text { Produksi } & =\text { Produktivitas GKG } \times \text { Luas Panen } \\
& =69,488 \times 2474,802 \\
& =17.1969 \text { Ton }
\end{aligned}
$$




\section{E. PENUTUP}

\section{Kesimpulan}

1. Hasil dari interpretasi lahan sawah dengan citra worldview 2, mengambil 20 titik sampel lahan sawah sehingga mendapatkan ketelitian 90\%, dengan 18 titik benar dan 2 titik salah. Hasil interpretasi cutra tersebut menghasilkan peta lahan sawah Kecamatan Sungai Raya dengan skala $1: 60.000$.

2. Hasil dari perhitungan luas dengan menggunakan calculate geometry, luas lahan sawah di kecamatan Sungai Raya adalah $2474,802 \mathrm{Ha}$.

3. Dari acuan luas lahan sawah eksisting yang di dapat dari perhitungan calculate geometry dan dari dari data hasil panen perhektar maka diperoleh hasil estimasi panen padi sebesar 17.1969 Ton dengan menggunakan motede ubinan

\section{Saran}

Perlu adanya perbaikan pada penelitian yang sama, menggunakan citra dengan tahun yang terbaru dan saat kondisi siap panen, agar lebih mudah dalam menginterpretasi.Diharapkan aplikasi analisa digital data penginderaan jauh berupa citra satelit Landsat7 ETM+ dan data DSM SRTM lebih luas lagi, dalam mengidentifikasi lokasilokasi berpotensi bahan tambang lainnya, tidak hanya batubara.

\section{F. DAFTAR PUSTAKA}

1. Atom, Siana. Pengertian Sawah danMacam macam Sawah. (2014) (http://www.artikelsiana.com/2014/11/penger tia -sawahmacam-macam-sawah/ diakses 22 Maret 2016).

2. Danoedoro, Projo. 1996. Pengolahan Citra Digital : Teori dan Aplikasinya dalam Bidang Penginderaan Jauh. Fakultas Geografi Universitas Gadjah Mada. Yogyakarta.

3. Said.H.S, Subiyanto.S, Yuwono. B.D., 2015. Analisa Produksi Padi dengan Penginderaan Jauh dan Sistem Informasi Geografis di Kota Pekalongan. Program Studi Teknik Geodesi Fakultas Teknik Universitas Diponegoro. Semarang Ismail, Pratama. 2012. Penyusunan Citra Komposit Warna. Yogyakarta.

4. Subrata, dan R. Kusmana. 2003. Koreksi Terhadap Cara Pengukuran Ubinan Tanaman Padi. Balai Pengkaji Teknologi Pertanian. Jawa Barat. BuletinTeknik Pertanian Vol. 8. No. 1.

5. Sutanto. Penginderaan Jauh Jilid 1. Universitas Gajah Mada Press. Yogyakarta. (1998).
6. Wells, Risdy. Pengolahan Citra Digital. (2010).(http://www.academia.edu/7385678/P engolahan_Citra_Digital/ diakses/ 02 April 2016). 